\title{
Transformatör sisteminde manyetik akı dağılımının incelenmesi yöntemiyle güç kayıplarının belirlenmesi
}

\author{
Aykut ILGAZ ${ }^{1, *}$, Mehmet BAYIRLI ${ }^{1}$, Mehmet AYGÖREN ${ }^{2}$ \\ ${ }^{1}$ Balıkesir Üniversitesi Fen Edebiyat Fakültesi, Çă̆lş kampüsü, Balıkesir. \\ ${ }^{2}$ Balıkesir Üniversitesi Fen Bilimleri Enstitüsü, Çağış kampüsü, Balıkesir.
}

Gelis Tarihi (Recived Date): 05.05.2016

Kabul Tarihi (Accepted Date): 18.05.2017

\section{Özet}

Transformatör sistemlerinde kullanılan malzemelerin manyetik akı dağılımlarının deneysel incelenmesi, sistemin yapısal ve fiziksel özelliklerinin belirlenmesi için önemlidir. Bu amaçla, özel olarak geliştirilen deneysel sistemde transformatörün çekirdeğini oluşturan silisyum-demir (SiFe) levhalardaki manyetik akı davranışı dairesel sensörler yardımıyla incelenmiştir. Manyetik akı dağılımı hesaplama yöntemi kullanilarak malzemenin manyetik indüksiyon-manyetik alan (B-H) karakteristiği çıkarılmıştır. B-H karakteristiğinden, malzemeden en yüksek verimin alınabileceği optimum manyetik indüksiyon değeri belirlenmiştir. Bunun yanı sıra boşta çalışma durumunda meydana gelen demir kayıplarl Histerisiz ve Fuko kayıplar olarak hesaplanmıştır. Bu çalışma çerçevesinde transformatörün yapımında kullanılan malzemenin demir kayıplarına etkisi araştırılmıştır. Hesaplanan demir kayıpları, imalat öncesi transformatörde düzeltme yapılmasına imkân sağlayarak maliyetin azalmasına yardımcı olmaktadır. Elde edilen sonuçlara göre boşta çalışma durumunda kaybedilen enerjinin çok büyük kısmının Histerisiz ve Fuko kayıpları nedeniyle meydana gelirken bakır kayıpları ihmal edilecek düzeyde olduğu belirlenmiştir.

Anahtar kelimeler: Transformatör, manyetik akl, demir kayıplarl, sensör, Histerisiz kaybı, Fuko kaybı

\footnotetext{
*Aykut ILGAZ, aykut17ilgaz@gmail.com, http://orcid.org/0000-0002-9632-0281

Mehmet BAYIRLI, mehmetbayirli@yahoo.com, http://orcid.org/0000-0002-7775-0251

Mehmet AYGÖREN, mehmetaygoren@gmail.com, http://orcid.org/0000-0002-6443-0742
} 


\title{
The determination of power losses in transformer system with magnetic flux distribution investigation method
}

\begin{abstract}
It is important to investigate experimentally magnetic flux distributions of used materials in the transformer systems for determining structural and physical properties of system. For this purpose, magnetic flux behavior in silicon-iron (SiFe) tin plates forming core of the transformer has been investigated via circular sensors. Magnetic induction-magnetic field characteristic $(B-H)$ of the material was obtained using the magnetic flux distribution calculation method. The optimum magnetic induction value was determined from $B-H$ characteristic in order to get the maximum efficiency. Besides that, iron losses which occur at no-load operation were calculated as Hysteresis and Faucolt losses. In this framework, the effect of the material used in the construction of the transformer on iron losses was investigated. The calculated iron losses help to reduce the cost enabling corrections in the transformer before manufacturing.
\end{abstract}

Keywords: Transformer, magnetic flux, iron losses, sensor, Hysteresis losses, Faucolt losses.

\section{Giriş}

Endüstriyel alanlarda ve günlük yaşantıda enerjiye olan bağımlılık günden güne artmaktadır. Bu ihtiyacı karşılamak için hidroelektrik, termik, jeotermal ve nükleer santraller gibi çeşitli tesisler kurulmaktadır [1]. Kurulan bu enerji santralleri ihtiyacı büyük oranda karşılasa da maliyet açısından masraflı ve verimliliği sınırlıdır. Bundan dolayı ilk aşamada yeni tesisler açmaktansa, var olan enerjinin nasıl verimli bir şekilde kullanılacağı bilimsel çalışmalara konu teşkil etmektedir.

Santrallerde üretilen elektrik enerjisinin şehirlere taşınmasında ve evlere verimli bir şekilde dağıtımında transformatör sistemleri kullanılmaktadır [2]. Hareketli parçaları olmayan ve stabil olarak çalışan transformatör sistemlerinde gelişen teknolojiye paralel olarak verimlilik sınırları günden güne yukarıya taşınmaktadır. Transformatörün yapısında bulunan ferromanyetik malzemelerin özelliklerinin iyileştirilmesi, malzemenin boyutlarının küçültülmesi, yapı içinde bulunan yabancı maddelerin uzaklaştırılması, nüve geometrisinin değiştirilmesi verimliliğin arttırılması için yapılan başlıca işlemlerdendir [3-8] . Bunun yanı sıra transformatör sistemlerindeki kayıpların belli bir kısmı kullanılan ferromanyetik malzemenin manyetik indüksiyon davranışından kaynaklanır. Bu nedenle malzemenin manyetik alana karşı davranışı belirlendiği zaman transformatör uygulamaları için uygun malzeme olup olmadığ anlaş1labilir. Böyle bir deneysel ön inceleme, üretim aşamasından önce düşük kayıplı transformatör tasarımı için yardımcı olabilir.

$\mathrm{Bu}$ çalışmada, model bir transformatör tasarlanarak farklı sensör grupları ile transformatörün üzerinde ve köşelerindeki manyetik akı dağılımları çıkarılmıştır. Bu akı haritasından yararlanılarak kaçak akı kayıpları elde edilmiş ve boşta çalışma durumunda demir nüvede meydana gelen güç kayıpları hesaplanmıştır. 


\section{Deneysel çalışmalar}

\subsection{Malzeme}

Manyetik güç kayıplarını ölçmek için kullanılan transformatör modelinin ölçeklendirilmiş hali Şekil 1'de görülmektedir. Çalışma kapsamında hazırlanan transformatörün demir çekirdeği kare şeklinde olup bir kenarı $90 \mathrm{~cm}$ dir. Levha genişliği ise $20 \mathrm{~cm}$ olup içteki boş alan $50 \mathrm{~cm} \times 50 \mathrm{~cm}$ boyutlarındadır. Kalınlığı $3 \mathrm{~cm}$ olan transformatörü manyetize etmek için 50 sarımlı bir primer bobin kullanılmıştır.
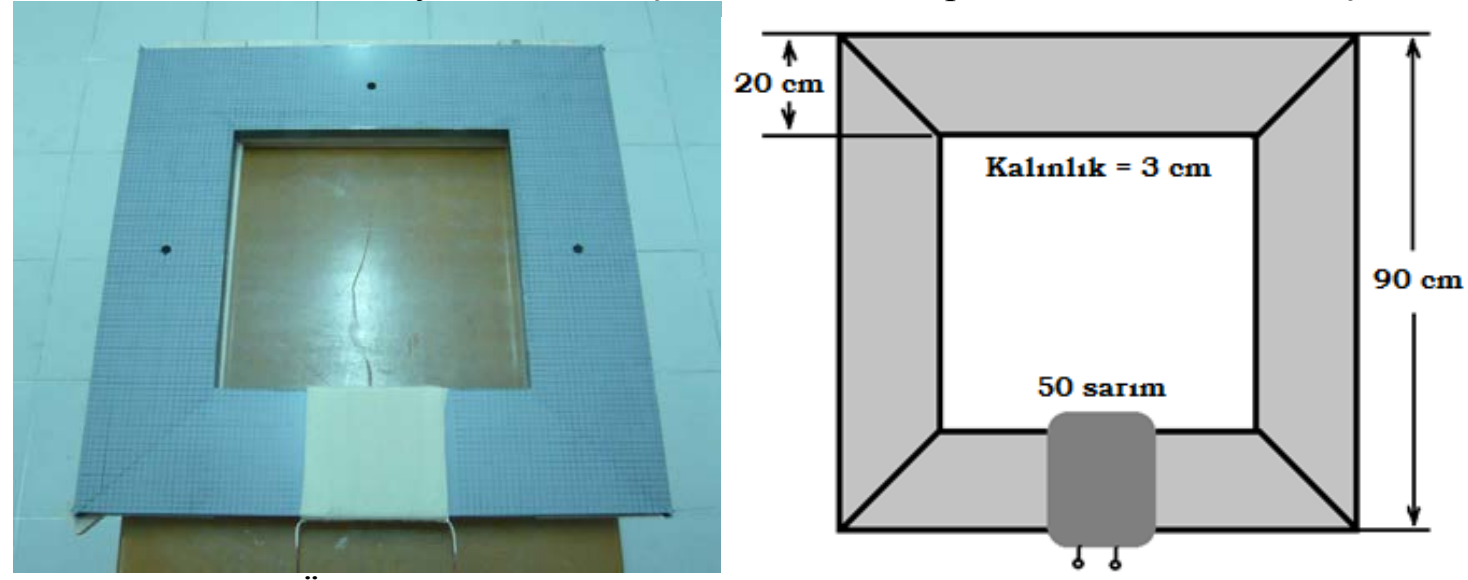

Şekil 1. Ölçümlerde kullanılan ölçeklendirilmiş transformatör modeli.

Transformatörü oluşturan levhalar, \%3 Silisyum (Si) içeren Silisyum-demir (SiFe) yapıda ve [100] yönünde yönlendirilmiş malzemelerden üretilmiştir. Bu malzemenin sadece $\mathrm{X}$ - doğrultusunda bileşeni bulunan [100] yönünde yönlendirilmesinin amacı demirin kolay mıknatıslanma yönünün [100] doğrultusunda olmasından kaynaklanmaktadır. Malzemenin manyetik özelliklerinin ölçümlerinde Uluslar arası Elektroteknik Komisyonu (International Electrotechnical Commission-IEC) standartlar prosedürü izlenmektedir. Kullanılan malzemenin IEC tanımı M130-3055 dir [9].

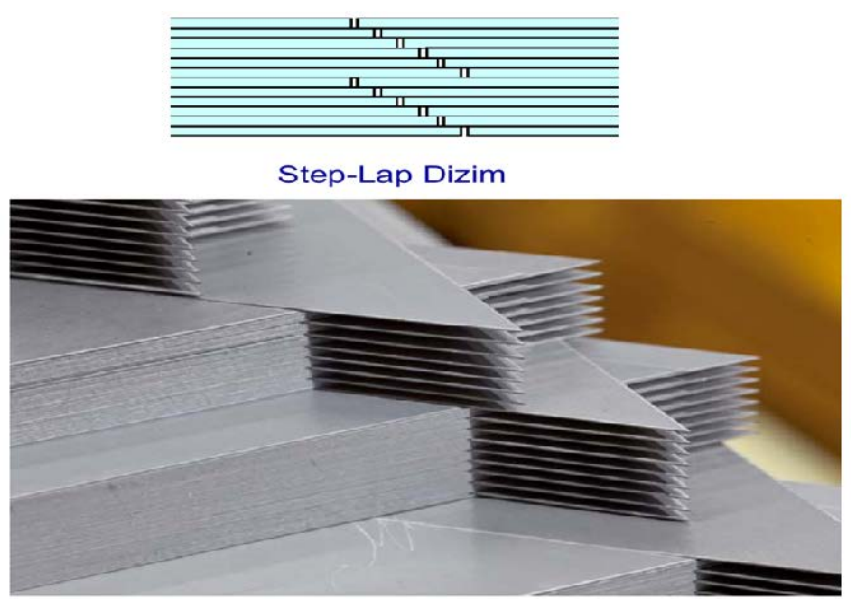

Şekil 2. İmal edilen modelde step-lap tasarım uygulaması

Oluşturulan transformatörde dairesel dizilim deliklerinin oluşturulması ve aynı zamanda üretimin etkin biçimde sağlanabilmesi için kademeli yap1 (step-lap) denilen tasarım tekniği ile farklı kesitlerdeki sac grupları Şekil 2'de görüldüğü gibi üst üste dizilmiştir. 
$\mathrm{Bu}$ tasarım tekniği kullanılarak demir kayıplarının minimum düzeye indirilmesi hedeflenmiştir [10].

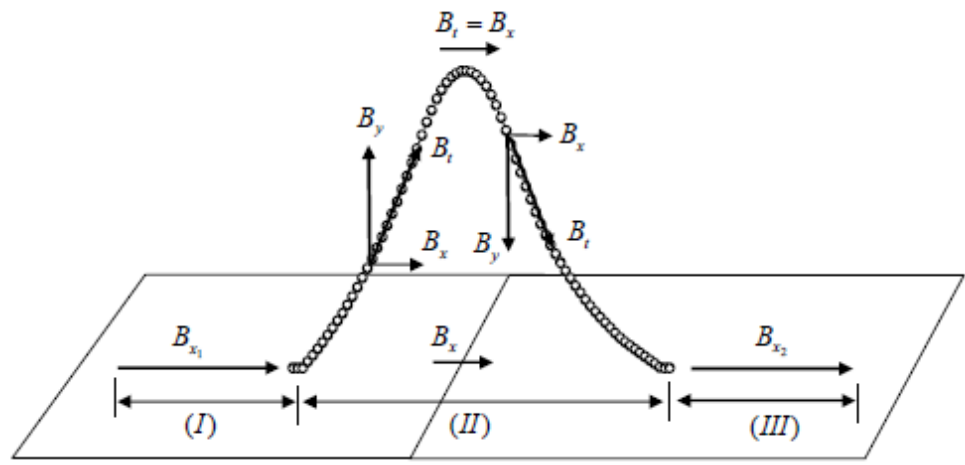

Şekil 3. Manyetik akının karşılaştığı süreksizliğe bağlı olarak gösterdiği davranış

Manyetize edilen transformatör levhaları üzerinde akan manyetik akı her zaman levha yüzeyinden akmayı tercih edecektir. Şekil 3'de görüldüğü üzere (I) ve (III) numaralı bölgelerde sürekli levha üzerinde akan manyetik akı, (II) numaralı bölge içinde bir süreksizlikle karşılaştığında var olan manyetik akının büyüklüğü $\overrightarrow{\boldsymbol{B}}_{\boldsymbol{x}}$ ve $\overrightarrow{\boldsymbol{B}}_{\boldsymbol{y}}$ olmak üzere iki bileşene ayrılır. Manyetik akının $\overrightarrow{\boldsymbol{B}}_{\boldsymbol{x}}$ bileşeni levha yüzeyine paralel yönde ortaya çıkmış olup $\overrightarrow{\boldsymbol{B}}_{\boldsymbol{y}}$ bileşeni ise levha yüzeyine dik yönde ortaya çıkmıştır. Manyetik akının bu şekildeki davranışı levha üzerinde bir süreksizlikle karşılaşıldığında hemen levha yüzeyine dik bir bileşen oluşturma eğilimi içinde olduğunu göstermektedir. $\mathrm{Bu}$ dik bileşen ise numunenin hemen üzerine yerleştirilmiş sensörler yardımıyla algilanmaktadır.

\subsection{Deneysel Düzenek}

Transformatörün B-H eğrisini çıkarmak için Şekil 4'te görülen deney düzeneği kurulmuştur. Seri R1 ve C1 devre elemanları transformatörün akısını gösterir. R2 direnci ile transformatörün çektiği akım algılanır. Algılanan akım manyetik alan şiddetini ifade eder. Böylece kullanılan osiloskobun 1. kanalı akımı 2.kanalı akı göstereceğinden elde edilen veriler yardımıyla B-H eğrisi elde edilir.

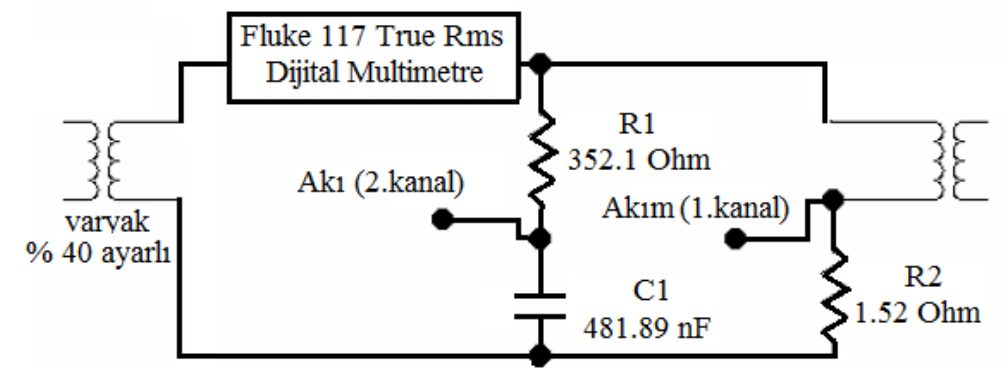

Şekil 4. B-H eğrisini çıkarmak için devre şeması 


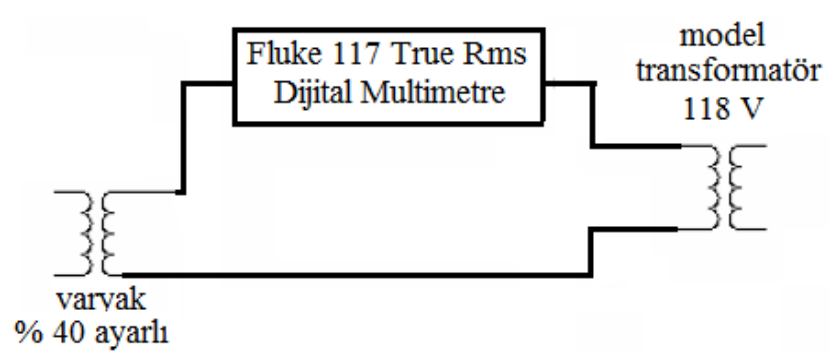

Şekil 5. Transformatörün demir kayıpları için hazırlanan devre şeması

Şekil 5'de boşta çalışma kayıplarını ölçmek için kurulan deney düzeneği görülmektedir. Kullanılan varyak ile transformatörün gerilimi kontrol edilmiş ve maksimum $120 \mathrm{~V}$ değerindeki gerilime ulaşılmıştır. Dijital multimetre sayesinde veriler alınmış ve bilgisayara aktarılarak manyetik alan değerlerine karşılık gelen histerisiz ve Fuko kayıpları hesaplanmıştır.

\subsection{Teorik Bilgi}

Faraday İndüksiyon Yasası gereğince kapalı bir devrede meydana gelen akı değişimi, devrede indüksiyon elektromotor kuvveti indüklenmesine neden olur. Meydana gelen indüksiyon elektromotor kuvveti

$$
\varepsilon=-\mathbf{N} \frac{\mathbf{d} \varphi}{\mathrm{dt}}
$$

şeklinde ifade edilir. $N$ sarım sayısını, $\varphi$ manyetik akıyı ve t zamanı temsil etmektedir. Eksi işareti, indüklenen voltajın kendini meydana getiren akı değişimine zıt yönde olduğunu göstermektedir. Primer sargıya bir gerilim uygulandığında ideal olarak manyetik akı şöyle ifade edilir:

$$
\varphi=\Phi_{\max } \sin \omega \mathbf{t}
$$

Burada $\Phi_{\max }=\overrightarrow{\mathbf{B}} \cdot \overrightarrow{\mathbf{A}}$ şeklinde olup B manyetik indüksiyon, A incelenen kesit alanı ve $\omega$ açısal hızdır. Denklem (2), denklem (1)'de yerine yazılıp düzenleme yapılırsa transformatör sargılarında indüklenen elektromotor kuvveti

$$
\varepsilon=4.44 \cdot \mathrm{f} \cdot \mathrm{B} \cdot \mathrm{N} \cdot \mathrm{A}(\text { volt })
$$

olarak elde edilir. Denklemde f, manyetizasyon akımının frekansıdır.

Transformatörlerde demir, bakır, kaçak akı ve harmonik kayıpları gibi verimi azaltan etkiler mevcuttur [11]. Transformatörün boşta ve yüklü çalışma durumuna göre kayıplar iki ana grupta toplanır. Boşta çalışma durumundaki kayıplar demir kayıpları olarak adlandırılırken yüklü çalışma durumundaki kayıplar bakır kayıpları olarak adlandırılır.

Primere bir gerilim uygulandığında sekonderin yüksüz olma durumu boşta çalışma durumu olarak adlandırılır. Bu durumda transformatörün çekirdeğinde meydana gelen kayıplar demir kayıplarıdır.

Girişe bir gerilim uygulandığı zaman ferromanyetik nüve içindeki domen adı verilen mikroskobik yapılar alan doğrultusunda yönelimlerini değiştirmeye çalışırlar. Bu sırada 
birbirleri ile sürtünmeleri sonucu 1sı şeklinde bir enerji kaybı meydana gelir. Histerisiz kaybı adı verilen bu kayıp şöyle ifade edilir [11]:

$$
\mathrm{P}_{\mathrm{h}}=\mathrm{a} \cdot \mathrm{B}_{\max }{ }^{\mathrm{n}} \cdot \mathrm{f}(\mathrm{W} / \mathrm{kg})
$$

Burada a, malzemenin karakteristiğine bağlı olan histerisiz katsayısı olup a $=1 \times 10^{-5}$ olarak alınmıştır. n sabiti malzemenin türüne ve akı yoğunluğuna bağlı olarak değişen Steinmetz sabitidir ve bu çalışmada nüveyi oluşturan demir malzeme için değeri 1.6'dır [12]. $\mathrm{B}_{\max }$ ise nüvedeki manyetik indüksiyonun maksimum değeridir.

Manyetik bir gövde üzerine sarılmış olan bobinden frekansı zamana bağlı olarak değişen bir akım geçirildiği zaman Faraday indüksiyon yasasına göre gövde üzerinde bir gerilim indüklenir. İndüklenen bu gerilim akımın kapalı bir halka şeklinde dolaşmasına neden olur. Su yüzeyindeki girdaplara benzeyen bu akım halkalarına Fuko akımları (Eddy akımları) denir. Bu girdap akımları manyetik alan çizgilerinin dolanım yapmasını zorlaştırır. Transformatörün sağlıklı çalışmasını engelleyen bu akımların neden olduğu güç kaybı [11]

$$
\mathrm{P}_{\mathrm{e}}=\mathrm{K}_{\mathrm{e}} \cdot \mathrm{f}^{2} \cdot \mathrm{B}_{\max }^{2}(\mathrm{~W} / \mathrm{kg})
$$

şeklinde ifade edilir. Burada $\mathrm{K}_{\mathrm{e}}$ malzemeye bağlı olarak değişen Eddy akımı sabiti olup $\mathrm{K}_{\mathrm{e}}=1 \times 10^{-5}$ olarak alınmıştır.

Boşta çalışma durumunda primerden çok küçük bir akım geçtiği için nüvede meydana gelen bakır kayıpları ihmal edilecek kadar küçük olur ve toplam kayıp histerisiz ve Fuko kaybının toplamı şeklinde yazılabilir [11]:

$$
\mathrm{P}_{\text {bos }}=\mathrm{P}_{\text {his }}+\mathrm{P}_{\text {fuko }}
$$

\section{Bulgular}

Transformatörün çekirdeğinin mıknatıslanma eğrisi Şekil 6'da görülmektedir. Görüldüğü gibi düşük alan bölgesi doğrusal bölge olarak adlandırılmıştır. Bu bölge mıknatıslanmanın sağlandığı yerdir. Bununla birlikte alan artmaya devam ettikçe manyetik akı yoğunluğu artık aynı oranla artmaz. Oranın değiştiği bu nokta büküm noktasıdır. Bu noktadan ileriye gidildikçe manyetik alan artsa bile akı yoğunluğu bu değişime aynı oranda karşılık veremez ve doyuma ulaşır.

Bir transformatör tasarımı yapılırken gerekli manyetik akı yoğunluğu (B) değeri doğrusal ve doyum bölgesinde seçilmemelidir. Doğrusal bölgede B değerinin küçük olması nüvenin kesit alanının büyümesine ve dolayısıyla gücün azalmasına yol açar. Yüksek indüksiyon değerlerinde yani doyum bölgesinde bobinlerin aşırı yüklenmesi nedeniyle ciddi ısınma problemleri ortaya çıkar. Ortaya çıkan 1sı enerjisi ise bakır kayıplarını arttırarak verimin düşmesine neden olur. Bu nedenlerden dolayı manyetik indüksiyon büküm bölgesinde seçilir. Büküm bölgesinde malzemenin optimum özelliklerine ulaşılır ve kayıplar en az seviyeye indirilerek en büyük verim değerine ulaşılır. Bu çalışmada da hesaplamalar için alınan optimum indüksiyon değeri büküm noktasında olup yaklaşık $1.5 \mathrm{~T}$ civarındadır. 


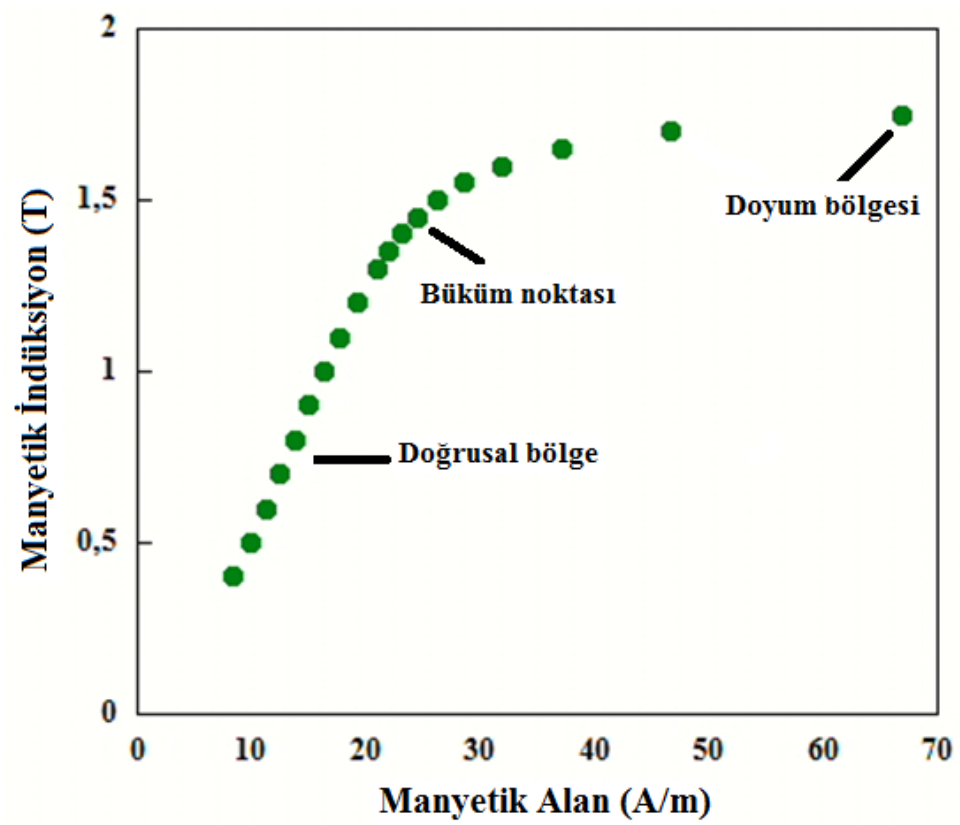

Şekil 6. Transformatör çekirdeğinin mıknatıslanma eğrisi

Ferromanyetik malzeme mıknatıslandığında, manyetik nüve içindeki alanların yönelimleri değişmeye başlar ve bu moleküller birbirlerine değerek ve sürterek bir 1s1 enerjisi açığa çıkarırlar. Statik kayıp olarak da adlandırılan histerisiz kaybının manyetik alan ile değişimi Şekil 7'de görülmektedir. $8 \mathrm{~Wb} / \mathrm{m}^{2}$ lik manyetik alan uygulandığ 1 zaman malzemede $0.01 \mathrm{~W} / \mathrm{kg}$ değerinde histerisiz kaybı meydana gelir. Artan manyetik alan ile birlikte bu kayıplar da artar ve yaklaşık $67 \mathrm{~A} / \mathrm{m}$ lik alan değerine ulaşıldığ zaman bu kayıp $0.12 \mathrm{~W}$ değerine çıkar.

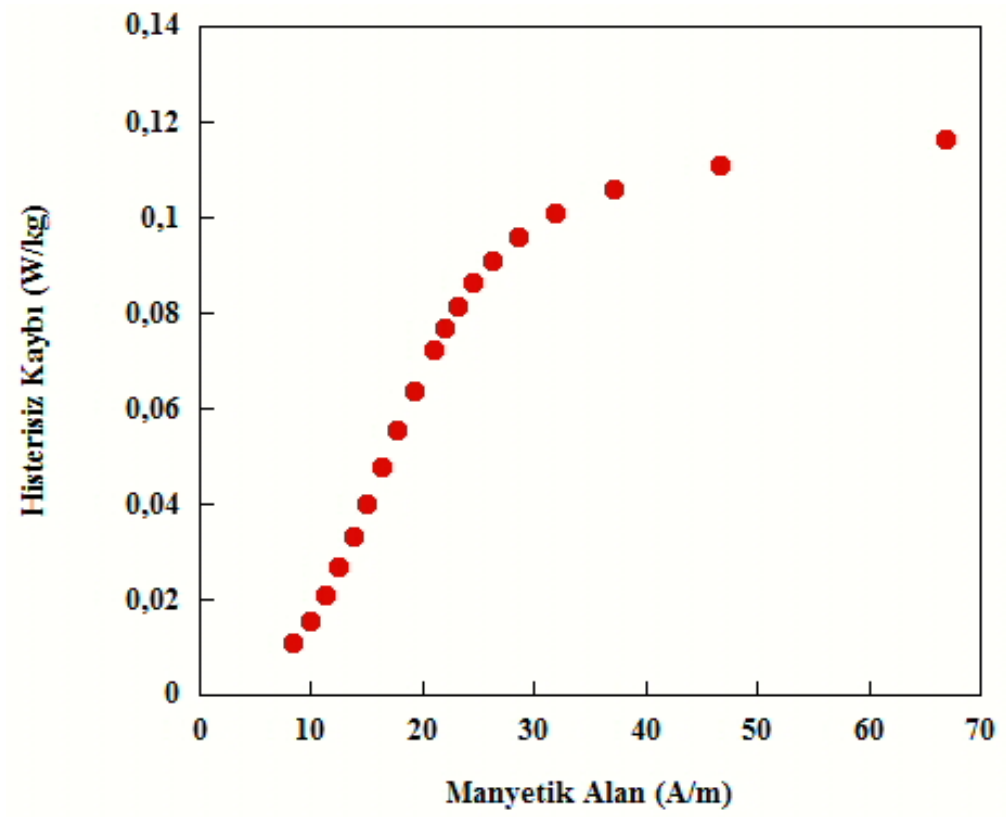

Şekil 7. Histerisiz kaybı 
Şekil 8, Fuko akımları nedeniyle transformatörde meydana gelen kaybın manyetik alanla değişimini göstermektedir. Nüve üzerinde indüklenen akı yoğunluğunun zamana göre değişmesinden kaynaklanan Fuko kaybı düşük manyetik alanlarda $0.02 \mathrm{~W} / \mathrm{kg}$ seviyelerinde iken manyetik alan artışı malzemedeki indüklenen akımı ve gerilimi arttırarak Fuko kayıplarının da artmasına neden olur. Bu durumda girdap akımları manyetik alan çevrimini zorlaştırarak kaybın yaklaşık $0.48 \mathrm{~W} / \mathrm{kg}$ 'a çıkmasına neden olur.

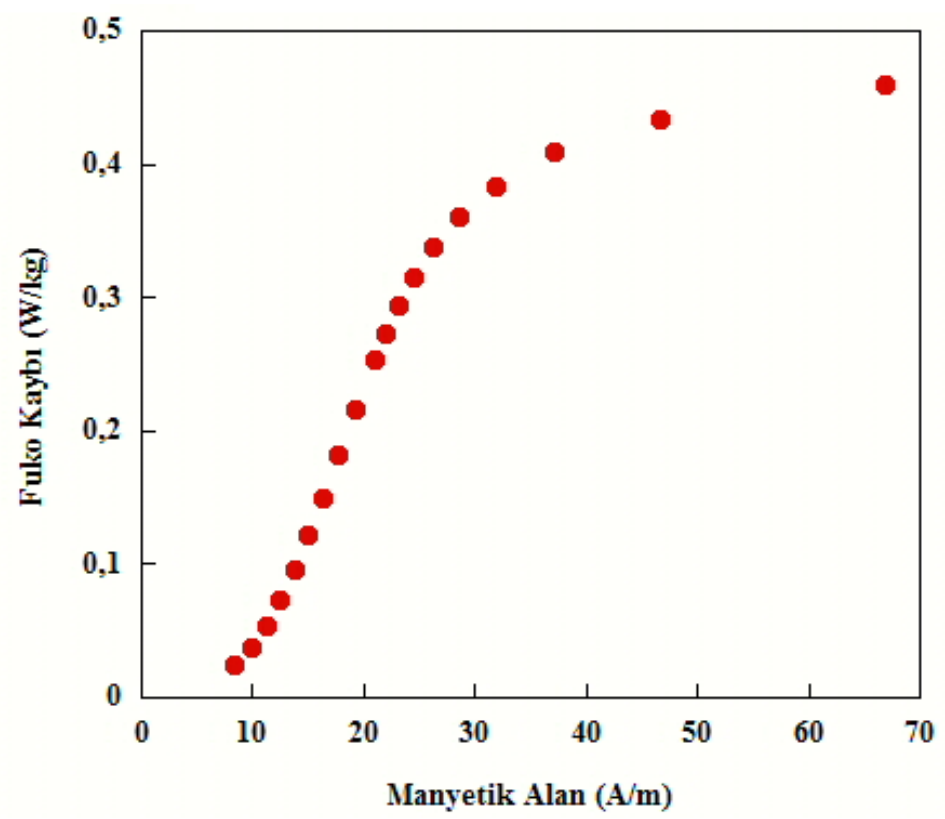

Şekil 8. Fuko kaybı

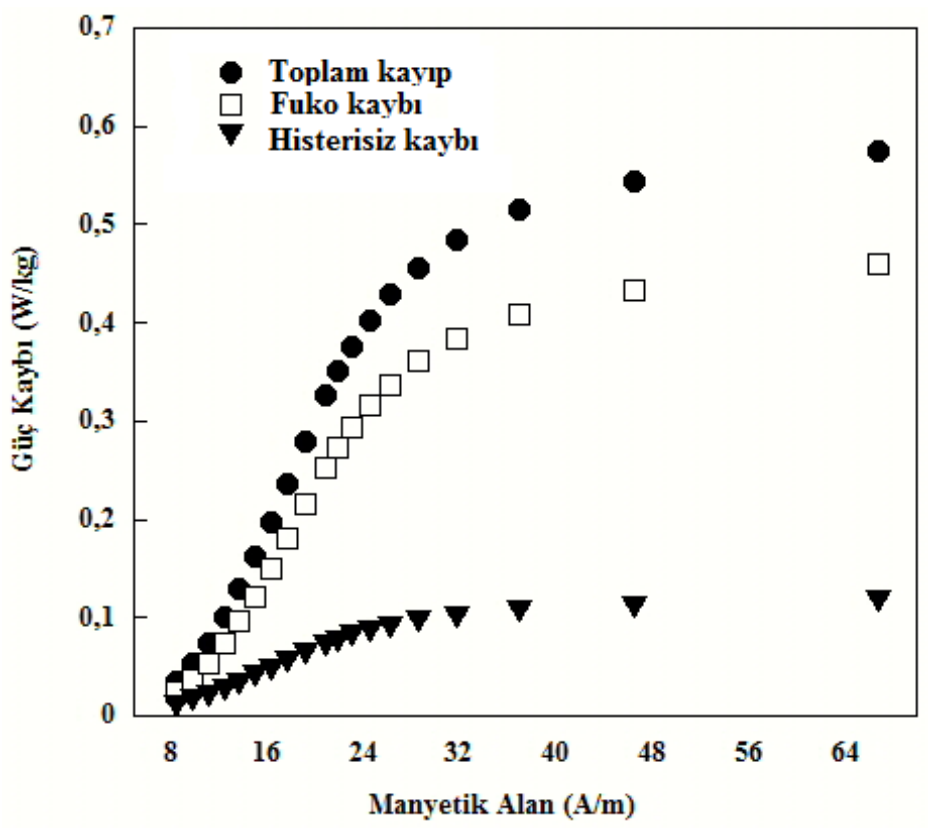

Şekil 9. Boşta çalışma kayıpları

Şekil 9, manyetik çekirdekte meydana gelen güç kayıplarını karşılaştırmalı olarak göstermektedir. Uygulanan voltaja bağlı olarak değişen boştaki demir kayıpları artan manyetik alan ile doğru orantılı olarak artmaktadır. Şekilde görüldüğü gibi malzemede 
oluşan Fuko kaybı manyetik alanın her değeri için histerisiz kaybından daha çoktur. Bu fark düşük alanlarda küçük değerde iken özellikle artan manyetik alanda malzemede indüklenen gerilimin artmasıyla birlikte Fuko kayıpları daha baskın hale gelmektedir.

\section{Sonuç ve tartışma}

Bu çalışmada \%3 Si içeren $\mathrm{SiFe}$ malzemelerden oluşan transformatörde boşta çalışma durumunda meydana gelen demir kayıpları ve malzemenin manyetik akı dağılımı incelenerek belirlenmiştir. Elde edilen sonuçlara göre boşta çalışma durumunda kaybedilen enerjinin çok büyük kısmının Histerisiz ve Fuko kayıpları nedeniyle meydana gelirken bakır kayıpları ihmal edilecek düzeyde olduğu belirlenmiştir. Manyetik alan artışı her iki kayıp türünü arttırırken yüksek alanlara doğru Fuko kaybı daha baskın hale gelmektedir. Yüksek manyetik alanlarda toplam kayıp yaklaşık olarak $0.60 \mathrm{~W} / \mathrm{kg}$ olarak bulunmuştur. Takip edilen IEC prosedürüne göre $50 \mathrm{~Hz}$ 'de çalıştırılan bir transformatör için $1.7 \mathrm{~T}$ değerindeki manyetik akı yoğunluğunda toplam güç kayb1 $1.32 \mathrm{~W} / \mathrm{kg}$ olarak verilmektedir. Buna göre demir kayıpları toplam kaybın yaklaşık olarak yarısını oluşturmaktadırlar. Geriye kalan kayıpların bakır kayıplarından ve kaçak akı kayıplarından kaynaklanmış olabileceği düşünülmektedir.

$\mathrm{Bu}$ kayıpların önceden hesabının yapılması, imalat aşamasından başlayarak transformatörlerin fiziksel ve yapısal özelliklerinin gelişimine katkıda bulunacaktır. Bu özelliklerin gelişimi ile transformatörlerin verimlerinde önemli kazanımlar elde edilecektir. Manyetik nüveyi oluşturan sacların kalınlığının $\mathrm{d}=3 \mathrm{~cm}$ den daha düşük değerlere çekilmesinin Fuko kayıplarını azaltacağı düşünülmektedir. Bunun yanı sıra manyetik nüve geometrisinin, anizotropi özelliklerinin ve kalınlığının bu kayıplar üzerindeki etkisi araştırılırsa kayıpların daha da azaltılabileceği buna bağlı olarak da verimin artacağı düşünülmektedir. Ayrıca silisyum katkısının değiştirilmesinin de direnci arttırarak kayıpları makul seviyelere çekeceği öngörülmektedir.

\section{Kaynaklar}

[1] Grimmond, W., Moses, A. J. ve Ling, P. C. Y., Geometrical factors affecting magnetic properties of wound toroidal cores, IEEE Transactions on Magnetics, 25, 3, (1989).

[2] Fiorillo, F. ve Novikov, A., An improved approach to power losses in magnetic laminations under non-sinusoidal induction waveform, IEEE Transactions on Magnetics, 26, 5, 2904-910, (1990).

[3] Kumar, H. and Sharma, S., How to Minimize Iron Losses in Transformer, International Journal of Scientific Research Engineering \& Technology, 1, 1, 36-42, (2012).

[4] Gençoğlu, M., Elektrik Enerjisi İletiminde Kayıpların Azaltılması, Kaynak Elektrik, 128-132, (2004).

[5] A. Basak, C. Higgs, Flux distribution in three phase transformer cores with various T-joint geometries, IEEE Transactions on Magnetics, 18, 670-673, (1982).

[6] Daneshmand, S. V., Heydari, H., Hysteresis Loss Improvement in HTS Transformers Using Hybrid Winding Schemes, IEEE Transactions on Applied Superconductivity, 22, 5500307, (2012). 
[7] Aleem, S., Balci, M. E., Sakar, S., Effective Utilization of Cables and Transformers Using Passive Filters For Non-linear Loads, International Journal of Electrical Power \& Energy Systems, 71, 344-350, (2015).

[8] Orosz, T., Sleisz, A., Tamus, Z. A., Metaheuristic Optimization Preliminary Design Process of Core-Form Autotransformers, IEEE Transactions on Magnetics, 52, 1-10, (2016).

[9] http://www.thyssenkrupp-steel.com/media/content_1/publikationen, (2015).

[10] Valkovic, Z., Rezic, A., Improvement of transformer core magnetic properties using the step-lap design, Journal of Magnetism and Magnetic Materials, 112, 413-415, (1992).

[11] Demir A, SST Yöntemi ile Nüve Malzemelerin Manyetik Kayıplarının Ölçülmesi, Yüksek Mühendislik Tezi, Bülent Ecevit Üniversitesi Fen Bilimleri Enstitüsü, Zonguldak, (2012).

[12] Mahmoud, S. K., Yağlı Dağıtım Transformatörlerde Kayıpların Hesaplanması, Yüksek Lisans Tezi, Gazi Üniversitesi Fen Bilimleri Enstitüsü, Ankara, (2008). 